\title{
Effect of Core Stabilization Exercises on Balance Performance in Older Adults
}

\author{
Ketki Ponde ${ }^{1}$, Ronika Agrawal ${ }^{2}$, Nazneen Khalil Chikte ${ }^{3}$ \\ ${ }^{1}$ Associate Professor, M.A.Rangoonwala College of Physiotherapy and Research, Pune, ${ }^{2}$ Principal and Professor, \\ M.A.Rangoonwala College of Physiotherapy and Research, Pune, ${ }^{3}$ Intern, M.A.Rangoonwala College of \\ Physiotherapy and Research, Pune
}

\begin{abstract}
Objective: Fall is defined as unintentional loss of balance that leads to failure of postural stability. Around $30 \%$ of older adults aged over 65 years have an episode of falls each year.. All postural control components undergo changes with ageing. Any impairment in neuromuscular, central nervous system and sensory system leads to fall. So the aim of present study was to determine the effects of Core stabilization exercises on balance performance in older adults. Methodology: Sixty participants both males and females aged between $65-75$ years were divided into 2 groups, Experimental and Control group $(n=30)$. Experimental group performed core stabilization exercises 5 times a week for 6 weeks, while control group carried on their routine daily activity for 6 weeks. Berg Balance Scale (BBS), Y-Balance Test, Functional Reach Test were assessed at the baseline and after 6 weeks of intervention. Results: Statistical analysis revealed that Experimental group showed significant improvement in BBS, Y - Balance Test and Functional Reach Test scores with $(\mathrm{p}<0.05)$ post 6 weeks of intervention. Control group showed no significant improvement in the scores. Conclusion: Core stabilization exercises had significant improvement on balance variables in experimental group when compared to control group.
\end{abstract}

Key words: Core, balance, older adults, fall, trunk muscles.

\section{Introduction}

Individuals above 65 years of age are considered to be older adults. Around $30 \%$ of older adults population aged over 65 years have an episode of falls each year ${ }^{[1]}$. As the age advances there are physiological changes which lead to lack of proprioception, reduced muscle strength, decline in reflex reaction to sudden changes, reduced sense of equilibrium, vision and decreased cognitive ability. ${ }^{[2][3]}$ Ageing is associated with decline in balance ability and muscle strength which causes

\footnotetext{
Corresponding Author:

Dr. Ketki Ponde (PT),

Associate Professor, M.A.Rangoonwala College of Physiotherapy and Research, Pune.

Address : 2390, K.B Hidayatullah road, Azam Campus, Pune-411001. Contact no: (020)26437879

E-mail id: drketki85@gmail.com
}

movement and gait disorders leading to falls. ${ }^{[3]}$ Muscle strength is lost in the axial muscles i.e. core muscles along with distal muscles which make it difficult to maintain balance. ${ }^{[4]}$

Balance is the ability to maintain the body's center of gravity within the limits of stability as determined by the base of support. ${ }^{[5]}$ The ability to maintain balance is an integrated task of neuromuscular, central nervous system and sensory system. ${ }^{[1]}$ As the age advances, changes taking place in these systems leads to fall in older adults people.

In static and dynamic situations, balance is achieved by positioning body's Centre of Gravity (COG) over the Base of Support (BOS). ${ }^{[1]}$ Dynamic balance activities are the activities that cause the COG to move in response to muscle activity. ${ }^{[5]}$ Dynamic control is essential in many functional tasks and involves integration of proprioception, range of motion and strength. ${ }^{[5]}$ 
Trunk extensors, flexors, and lateral flexors provide spinal stability during every dynamic movement ${ }^{[6]}$ Impairments in trunk muscle such as decreased trunk strength or endurance, are likely to cause changes in balance and mobility status which leads to fall in older adults ${ }^{[7]}$ Corestability is maintained by increasing the activity of coresegmental muscles. ${ }^{[8]}$

Core muscles are the kinetic link that transfers the torques and angular momenta between upper and lower extremities during the execution of whole-body movements ${ }^{[9]}$ Global muscles( Rectus abdominis, external obliques and some parts of the erector spinae ) are ideal for creating movement of the trunk and producing torque, because of their large moment arms and long levers as they are attached from the thorax to the pelvis. ${ }^{[6]}$ These muscles are labelled as the prime movers for trunk or hip flexion, extension and rotation. During whole body movement stability of corespine is associated with Local muscles. ${ }^{[5]}$ Local muscles(Transversus abdominis, multifidus, pelvic floor, diaphragm and internal obliques ) are responsible for producing sufficient force for segmental stability of the spine. ${ }^{[5]}$ The co-ordinated muscle recruitment between the global muscles and the local muscles during functional activities maintains stability of the corespine. ${ }^{[8]}$ Corestabilization exercises helps in improving neuromuscular control, strength and endurance of the muscles ${ }^{[10]}$ Corestability training targets the muscles deep within the trunk which are connected to the spine, pelvis and shoulders and it assists in maintaining good posture and provides the foundation for arm and leg movements. ${ }^{[7]}$ Exercises that target core muscles are effective for corestabilization and motor control training and thus are used for maintaining balance. ${ }^{[3,11]}$

Studies suggested that core muscles play an important role in improving balance and training functional mobility in older adults individuals. ${ }^{[12]} \mathrm{A}$ study done by Suri et al., 2009 have shown associations between diminished trunk muscle strength, endurance, muscle quality, mobility and poor balance in older adults ${ }^{[7]}$ So the study aims to measure effect of corestabilization exercises on balance in older adults.

\section{Methodology}

The study was commenced after approval from Institutional ethics committee. Sixty geriatric participants both males and females aged 65-75 years whose Berg Balance Score was more than 40 and were functionally independent were included in the study. Participants were excluded if they had history of recent fractures of lower limb, spinal fractures in past 1 year and any cardiovascular and neurological impairment since past one year. Informed written consent from all the participants were taken after the explanation of the testing procedure, protocol and duration of the intervention. Participants were allocated into two groups i.e. Group (A) Experimental and Group (B) Control group. Group A was given core stabilization exercises like: Drawing in manuvers, Bent leg fall out, Drawing in manuvers along with a) Lift bent leg to 90degree hip flexion b) slide heel to extend knee c) straight leg raise to 45 degrees were given which help them to activate the deep segmental muscles along with their normal daily activities for 5 days week for 6 weeks, while Group B was not given any intervention and was told to carry out their regular routine for 6 weeks. All necessary precautions were taken in order to prevent any kind of fall during the testing procedure and intervention. The measurement of variables Berg Balance Scale, Functional Reach test and $\mathrm{Y}$ - Balance Test were taken pre training (o week) and post training (post training)

\section{Statistical Analysis}

Statistical analysis was done in statistical package for social sciences .Paired t- test was done for Intra group while un -paired t- test was done for Inter group comparison. 


\section{Results}

TABLE 1: Intra group comparison of Mean pre and post 6 weeks of intervention using paired t-test in Experimental Group.

\begin{tabular}{|c|c|c|c|c|c|}
\hline & \multirow[t]{2}{*}{ VARIABLES } & \multicolumn{2}{|c|}{ MEAN VALUE } & \multirow{2}{*}{ P VALUE } & \multirow{2}{*}{ t VALUE } \\
\hline & & PRE & $\begin{array}{l}\text { POST } 6 \\
\text { WEEKS }\end{array}$ & & \\
\hline 1 & Berg Balance Scale & 45.76 & 48.1 & $7.96 \mathrm{E}-17$ & -16.85 \\
\hline 2 & Y BALANCE TEST & & & & \\
\hline \multirow{3}{*}{ RIGHT } & ANTERIOR & 57.2 & 60.4 & $6.01 \mathrm{E}-08$ & -6.95 \\
\hline & POSTEROMEDIAL & 45.3 & 48.6 & 3.29 E-08 & -7.18 \\
\hline & POSTEROLATERAL & 34.16 & 37.2 & 4.81E-08 & -7.03 \\
\hline \multirow{3}{*}{ LEFT } & ANTERIOR & 57.13 & 60.26 & $6.31 \mathrm{E}-08$ & -6.93 \\
\hline & POSTEROMEDIAL & 44.13 & 47.06 & $3.47 \mathrm{E}-08$ & -7.16 \\
\hline & POSTEROLATERAL & 33.5 & 36 & 4.27E-09 & -7.9 \\
\hline 3 & Functional Reach Test & 18.16 & 20.8 & $1.14 \mathrm{E}-11$ & -10.4 \\
\hline
\end{tabular}

Interpretation: Post 6 weeks of exercises there was significant improvement seen in scores of Berg Balance scale $(p \leq 0.05)$, Y balance test $(p \leq 0.05)$ and Functional reach test $(p \leq 0.05)$

TABLE 2: Intra group comparison of Mean pre and post 6 weeks of intervention using paired t-test in Control Group

\begin{tabular}{|c|c|c|c|c|c|c|}
\hline \multicolumn{7}{|c|}{ CONTROL GROUP } \\
\hline & \multirow[t]{2}{*}{ VARIABLES } & \multicolumn{2}{|c|}{ MEAN VALUE } & \multirow{2}{*}{$\begin{array}{l}\text { P } \\
\text { VALUE }\end{array}$} & \multirow{2}{*}{ t VALUE } & \multirow{2}{*}{$\begin{array}{l}\text { INTERPRETATION OF } \\
\text { SIGNIFICANCE }\end{array}$} \\
\hline & & PRE & $\begin{array}{l}\text { POST } 6 \\
\text { WEEKS }\end{array}$ & & & \\
\hline 1 & BERG BALANCE SCALE & 45.6 & 45.33 & 0.13 & 1.13 & INSIGNIFICANT \\
\hline 2 & Y BALANCE TEST & & & & & \\
\hline \multirow{3}{*}{ RIGHT } & ANTERIOR & 55 & 54.6 & 0.14 & 1.09 & INSIGNIFICANT \\
\hline & POSTEROMEDIAL & 43.2 & 43.4 & 0.27 & -0.61 & INSIGNIFICANT \\
\hline & POSTEROLATERAL & 33.4 & 33 & 0.13 & 1.13 & INSIGNIFICANT \\
\hline \multirow{3}{*}{ LEFT } & ANTERIOR & 57.2 & 57.3 & 0.38 & -0.29 & INSIGNIFICANT \\
\hline & POSTEROMEDIAL & 42.5 & 42.8 & 0.28 & -0.58 & INSIGNIFICANT \\
\hline & POSTEROLATERAL & 33 & 32.6 & 0.13 & 1.12 & INSIGNIFICANT \\
\hline 3 & $\begin{array}{l}\text { FUNCTIONAL REACH } \\
\text { TEST }\end{array}$ & 17.73 & 17.43 & 0.08 & 1.42 & INSIGNIFICANT \\
\hline
\end{tabular}


Interpretation: Post 6 weeks intervention there was no significant improvement seen in the control group scores $(\mathrm{p} \geq 0.05)$

TABLE 3: Inter Group Comparison of Mean of Variables using Un- Paired t-test between Experimental and Control group

\section{INTER GROUP MEAN DIFFERENCE}

\begin{tabular}{|c|c|c|c|c|c|c|}
\hline & VARIABLES & $\begin{array}{l}\text { EXPERI- } \\
\text { MENTAL }\end{array}$ & CONTROL & P VALUE & t VALUE & \\
\hline 1 & $\begin{array}{l}\text { BERG BALANCE } \\
\text { SCALE }\end{array}$ & 2.33 & -0.33 & $3.2 \mathrm{E}-10$ & 8.23 & SIGNIFICANT \\
\hline 2 & Y BALANCE TEST & & & & & \\
\hline \multirow{3}{*}{ RIGHT } & ANTERIOR & 3.26 & -0.4 & $8.48 \mathrm{E}-08$ & 6.17 & SIGNIFICANT \\
\hline & POSTEROMEDIAL & 3.26 & 0.23 & $3.65 \mathrm{E}-08$ & 5.13 & SIGNIFICANT \\
\hline & POSTEROLATERAL & 3.1 & -0.46 & $1.87 \mathrm{E}-07$ & 5.91 & SIGNIFICANT \\
\hline \multirow{3}{*}{ LEFT } & ANTERIOR & 3.13 & 0.1 & $1.86 \mathrm{E}-06$ & 5.34 & SIGNIFICANT \\
\hline & POSTEROMEDIAL & 2.93 & 0.26 & $6.07 \mathrm{E}-05$ & 4.33 & SIGNIFICANT \\
\hline & POSTEROLATERAL & 2.5 & -0.33 & $1.58 \mathrm{E}-08$ & 6.56 & SIGNIFICANT \\
\hline 3 & $\begin{array}{l}\text { FUNCTIONAL } \\
\text { REACH TEST }\end{array}$ & 2.63 & -0.3 & $2.10 \mathrm{E}-12$ & 8.95 & SIGNIFICANT \\
\hline
\end{tabular}

Interpretation: Significant improvement was seen in experimental group compared to control group ( $\mathrm{p} \leq 0.05)$

\section{Discussion}

Core stabilization exercises were carried on experimental group for 6 weeks. The exercises showed significant improvement in balance as compared to control group. Improvement in balance could be due to core stabilization exercises that target the deep stabilizers of the spine which play a crucial role in providing a stable foundation upon which the limb muscles can move. ${ }^{[13]}$

The core stability system is the product of motor control and muscular capacity of lumbopelvic-Hip complex. It acts like a corset which gives tension to the trunk muscles when activated. These muscles are divided as local and global muscles. Global muscles like Erector spinae, rectus abdominis, external oblique and quadrates lumboram provides trunk motion with rapid and powerful torques. The local muscles consist of transverse abdominis, multifidus, internal oblique are situated deep which provide dynamic segmental spinal stability ${ }^{[15]}$.

Statistical analysis showed significant improvement in BBS score, Y balance test and Functional reach test post six weeks of intervention. This could be attributed due to TrA activation prior to and during lower limb activity which helps in reducing the perturbing forces on posture and balance ${ }^{[16]}$. Also the core stabilization exercises provide protection to the low back muscles that challenges the balance, flexibility and co ordination [17]. The exercises enabled improvement of reaction time which is important factor in optimal balance. The repetitive exercises and weekly progression helped in improving the endurance which was associated with 
balance performance. Rosa Cabanas et al suggested the positive association of central nervous system (CNS) stabilizing the spine through the contraction of trunk and pelvis muscle in response to reactive forces of lower limb. Panjabi also stated that contraction of core muscle activates the postural responses by CNS which help in controlling the balance.

Core stability exercises are effective in motor control training. The exercise recover the postural control function of body and increases the range of motion. So it can be considered as appropriate exercise for older adults.Motor learing which occurs during the core training improves muscle reflexes and accelerates proprioception which affects balance control.

Control group did not show any significant change in Berg Balance Scale, Y - balance Test (anterior,posteromedial, posterolateral) and Functional Reach Test. As Ageing is an on-going process, there are normal age associated changes taking place in the body which leads to impairments in balance ${ }^{[1]}$.Also, there is decline of physiological capacities and deterioration of ability to respond to stress in this period which increases vulnerability of the older adults to various impairments due to ageing process ${ }^{[4]}$. So there was no change seen in the control group.

\section{Conclusion}

Based on the findings from our study, we conclude that along with peripheral muscles strengthening exercises, core stabilisation exercises are also important in maintaining the balance in older adults.

Acknowledgement: we would like to acknowledge the Old Age Homes in Pune and the participants for giving their valuable time and allowing us to assess them.

\section{Source of Funding: NIL}

\section{Conflict of Interest: None}

\section{References}

1. Guccione A, Wong R, Avers D. Geriatric Physical

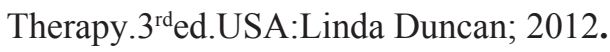

2. Kang K. Effects of core muscle stability training on the weight distribution and stability of the older adults. J. Phys. Ther. Sci.2015, July; 27(10):3163-
3165.

3. Kim N, Kim J, Wang J, Park J, Choi J. The effects of isometric trunk exercises and dynamic trunk exercises on gait in older adults people. J Phy Ther Sci 2015, June; 27(6) :1685 -1689.

4. Petrofsky J, Cuneo M, Dial R, Pawley K, Hill J. Core Strengthening and Balance in the Geriatric Population. The Journal of Applied Research. 2005;5(3):423-432.

5. Nicole K. The Effects of Core Stability Training on Balance Testing in Young, Healthy Adults.Toledo: Thomas; 2009.

6. Amira A, Abdallah A, BeltagiA.Effect of Core Stability Exercises on Trunk Muscle Balance in Healthy Adult Individuals. International Journal of Medical, Health, Biomedical, Bioengineering and Pharmaceutical Engineering 2014;8(5): 243-248.

7. Suri P, Kiely D, Leveille S, Frontera W, Bean J. Trunk Muscle Attributes Are Associated with Balance and Mobility in Older Adults: A Pilot Study. USA:National Institute of Health Public Access; 26-2009 October. 9 p.

8. O 'Sullivan P. Coresegmental 'instability': clinical presentation and specific stabilizing exercise management. Manual Therapy 2000; 5(11): 2-12.

9. Granacher U, Gollhofer A, Hortoba' gyi T, Kressig R, Muehlbauer T. The Importance of Trunk Muscle Strength for Balance, Functional Performance, and Fall Prevention in Seniors: A Systematic Review. Sports Med 2013, April ; 627-41.

10. Moon H, Choi K, Kim D, Kim H, Cho Y, Lee K et al .Effects of CoreStabilization and Dynamic CoreStrengthening On Patients with Chronic Low Back Pain. Ann Rehab Med 2013; 37 (1):110-117.

11. Kang K, Choi J, Lee S. Effects of Core Strengthening Exercises on Symmetrical Double Limb Support And Balance Ability For The Older adults. J IntAcad Phy Ther Res 2012, January;3(1):345-411.

12. Kahle N, Tevald A. Core Muscle Strengthening's Improvement of Balance Performance in Community-Dwelling Older Adults: A Pilot Study. Journal of Ageing and Physical Activity 2014 :6573.

14. KisnerC,Colby L. Therapeutic Exercise:Foundation and Technique. $6^{\text {th }}$ ed. Philadelphia:Jaypee Brothers; 2012.

15. Huxel Bliven KC, Anderson BE. Core stability 
training for injury prevention. Sports health. 2013 Nov;5(6):514-22.

16. Watson T, Graning J, McPherson S, Carter E, Edwards J, Melcher I, Burgess T. Dance, balance and core muscle performance measures are improved following a 9-week core stabilization training program among competitive collegiate dancers. International journal of sports physical therapy. 2017 Feb;12(1):25.
17. Kulkarni M, Agrawal R, Shaikh F. Effects of Core Stabilization Exercises and Core Stabilization Exercises with Kinesiotaping for Low Back Pain and Core Strength in Bharatanatyam Dancers. Indian Journal of Physiotherapy \& Occupational Therapy. 2018 Oct 1;12(4).

18. Bastani M, Ghasemi G, Sadeghi M, Afshon A, Sadeghi H. The Effect of Selected Core Stability Exercises on Balance and Muscle Endurance in the Older adults Patients Undergoing Hemodialysis. Physical Treatments-Specific Physical Therapy Journal. 2017 Jul 10;7(2):89-96. 